\title{
Beyond Quality and Accessibility: Source Selection in Consumer Health Information Searching
}

\author{
Yan Zhang \\ School of Information, University of Texas at Austin, 1616 Guadalupe, Austin, TX 78701. \\ E-mail: yanz@ischool.utexas.edu
}

\begin{abstract}
A systematic understanding of factors and criteria that affect consumers' selection of sources for health information is necessary for the design of effective health information services and information systems. However, current studies have overly focused on source attributes as indicators for 2 criteria, source quality and accessibility, and overlooked the role of other factors and criteria that help determine source selection. To fill this gap, guided by decision-making theories and the cognitive perspective to information search, we interviewed 30 participants about their reasons for using a wide range of sources for health information. Additionally, we asked each of them to report a critical incident in which sources were selected to fulfill a specific information need. Based on the analysis of the transcripts, 5 categories of factors were identified as influential to source selection: source-related factors, user-related factors, user-source relationships, characteristics of the problematic situation, and social influences. In addition, about a dozen criteria that mediate the influence of the factors on source-selection decisions were identified, including accessibility, quality, usability, interactivity, relevance, usefulness, familiarity, affection, anonymity, and appropriateness. These results significantly expanded the current understanding of the nature of costs and benefits involved in source-selection decisions, and strongly indicated that a personalized approach is needed for information services and information systems to provide effective access to health information sources for consumers.
\end{abstract}

\section{Introduction}

Information sources are containers or carriers of information (Kuhlthau, 1999; Morrison \& Vancouver, 2000; O'Reilly, 1982). Selecting a source is often the first step in information seeking (Belkin, Oddy, \& Brooks, 1982; Marchionini, 1997; Savolainen, 2006; Wilson, 1981). Thus,

Received December 19, 2012; revised March 10, 2013; May 13, 2013; accepted May 14, 2013

(C) 2014 ASIS\&T • Published online 7 January 2014 in Wiley Online Library (wileyonlinelibrary.com). DOI: 10.1002/asi.23023 source selection naturally has a direct impact on the success of information search attempts. This impact may be more significant in the health domain, as the quality and completeness of information varies greatly across different sources (Purcell, Wilson, \& Delamothe, 2002; Yeung \& Mortensen, 2012). Such variances could cause users to develop different mental models of diseases and form different health beliefs, which will subsequently lead to different health behaviors and decisions (Kealey \& Berkman, 2010).

Health information is available from many different sources. More traditional ones include interpersonal sources (doctors, family, and friends), mass media (TV, newspapers, magazines, and radio), published literature, books, pamphlets, and telephone advice lines (e.g., cancer information services) (Cangelosi \& Markham, 1994; Gollop, 1997; Lenz, 1984; Manfredi, Czaja, Buis, \& Derk, 1993; O’Malley, Kerner, \& Johnson, 1999; Pennbridge, Moya, \& Rodrigues, 1999). In the late 1990s, the diffusion of the Internet into the public sphere rapidly made it a popular space for general consumers to seek health information (Eysenbach, 2000; Morahan-Martin, 2004). More recently, the development of Web 2.0 technologies led to the emergence of an array of new forms of sources, including online communities, wikis, social Q\&A, and social networking sites (SNSs), where consumers not only look for information, but also share personal stories, participate in discussions, and collaboratively construct knowledge (Eysenbach, Powell, Englesakis, Rizo, \& Stern, 2004; Laurent \& Vickers, 2009; Oh, Yi, \& Worrall, 2012). This recent development has made the current health information environment unprecedentedly diverse and complex.

The availability of a wide variety of sources and the significant impact that a source has on one's health behavior and decisions invite a close examination of the criteria by which consumers select sources and the factors that influence that selection. This knowledge is necessary for informing health literacy education and for improving information services and the design of health information systems. Source selection is, by no means, a new research topic. As a matter of fact, much has been known about consumers' 
preferences and use of traditional and Internet-based sources for health information, and it is agreed that source selection is affected by many different factors, including sourcerelated features (e.g., quality and accessibility) and userrelated factors (e.g., age, income, and ethnicity) (Case, Johnson, Andrews, Allard, \& Kelly, 2004; Cline \& Haynes, 2001; Johnson \& Meischke, 1991). However, research gaps exist, one of which is that most studies have focused on users' selection and use of one particular source, primarily the Internet (Cline \& Haynes, 2001). Source selection criteria identified in these studies, therefore, are inevitably constrained by the characteristics of the source itself. This constraint prevents researchers from gaining a comprehensive understanding of source selection as a decision-making behavior that involves cost-benefit analyses of multiple options. Several studies have examined source selection across several sources (often three to four). However, these studies mostly used surveys, a method that has limited power in eliciting users' reasons for selecting a particular source over the others (Johnson \& Meischke, 1991; Smith, 2011).

The goal of this study is to fill this gap and achieve a more comprehensive and systematic understanding of factors that influence users' selection of sources for health information from a user-centered perspective. To reach this goal, we interviewed consumers about their source selection behaviors across a wide range of sources, including the newly emerged Web 2.0 social media. Thus, this study will also improve the current limited knowledge about users' perceptions and use of social media for health purposes.

\section{Literature Review}

In the area of health information seeking, one of the most commonly adopted models for studying source selection and use is the comprehensive model of information seeking (CMIS) (Johnson \& Meischke, 1991). The model postulates that users' selection of a particular information carrier for health information is affected by two major categories of factors: factors associated with features of sources (e.g., the utility of the source) (Han et al., 2010), and factors associated with users (including demographics, illness experience, and psychological needs) (Johnson, 1997). The remainder of this literature review is organized around these two categories.

Source characteristics may be the most studied category of factors that affect source selection. Among the factors, quality attracted the most attention due to the potentially detrimental impact of low-quality health information. Numerous studies suggest that, similar to their assessment of traditional print sources, users rely on various source cues, such as layout and appearance, disclosures, advertisements, references provided, editorial processes, and picture of the site owner, to evaluate web-based health information (Cline \& Haynes, 2001; Escoffery et al., 2005; Eysenbach \& Kohler, 2002; Eysenbach, Powell, Kuss, \& Sa, 2002; Griffiths \& Christensen, 2005; Silberg, Lundberg, \&
Musacchio, 1997; Toms \& Latter, 2007). Sillence, Briggs, Fishwick, and Harris (2004) went further and proposed a staged model to account for users' formation of trust in a health website and their selection of the site. At the first stage, users quickly reject certain websites, mainly based on design factors (e.g., layout and navigation aids); at the second stage, they select websites based on a meticulous appraisal of content/message factors (e.g., accuracy, topic coverage, and readability). For interpersonal sources, studies have demonstrated that health care providers, particularly physicians, are still the most trusted and preferred sources of health information because of their expertise (Baker, Wagner, Singer, \& Bundorf, 2003; Dolan, 2003; Fox \& Jones, 2009; Hesse et al., 2005; Johnson \& Meischke, 1991; O’Malley et al., 1999).

However, due to the scarcity of health care resources, consumers' actual use of sources is not always consistent with their preferences. Studying middle-class women who have undergone mammography for cancer-related information, Johnson and Meischke (1991) found that although doctors were ranked as the most preferred source and the media the least, the media were used the most in reality, followed by doctors, organizations, and family and friends. Similarly, based on the Health Information National Trends Survey (HINTS), Hesse et al. (2005) found that $49.5 \%$ of adults reported wanting to go to their physicians first, but only $10.9 \%$ actually did so, with $48.6 \%$ going online first. By interviewing consumers about their use of health sources when facing specific health problems, Zhang (2012b) found that doctors were often used at a later stage in the information-seeking process, mainly due to difficulties associated with making appointments. These empirical results point to the idea that consumers' actual use of sources, to a large degree, is constrained by source availability. Indeed, a longstanding explanation for source selection is the least effort principle, suggesting that accessibility, compared to quality, plays a dominant role in source selection (Fidel \& Green, 2004; Gerstberger \& Allen, 1968).

Numerous studies also point out that users turn to the web and online communities for their anonymity (Cline \& Haynes, 2001; Fox \& Jones, 2009), which has been cited as the factor that makes these digital sources ideal for potentially embarrassing or delicate topics such as sexually transmitted diseases (STDs), contraception, pregnancy, and weight loss (Gray, Klein, Cantrill, \& Noyce, 2002; Newman, Lauterbach, Munson, Resnick, \& Morris, 2011). In addition, two source characteristics, the ease of use and the usefulness of the content, were also identified as influencing consumers' selection of sources for health information (Cline \& Haynes, 2001; Escoffery et al., 2005). This result is consistent with the technology acceptance model (TAM) (Davis, 1989).

The impact of the second category, user-related factors, on source selection has also been extensively studied. Three major categories of user-related factors were investigated: demographics, illness experience, and psychological needs. For demographics, earlier studies suggest low power in 


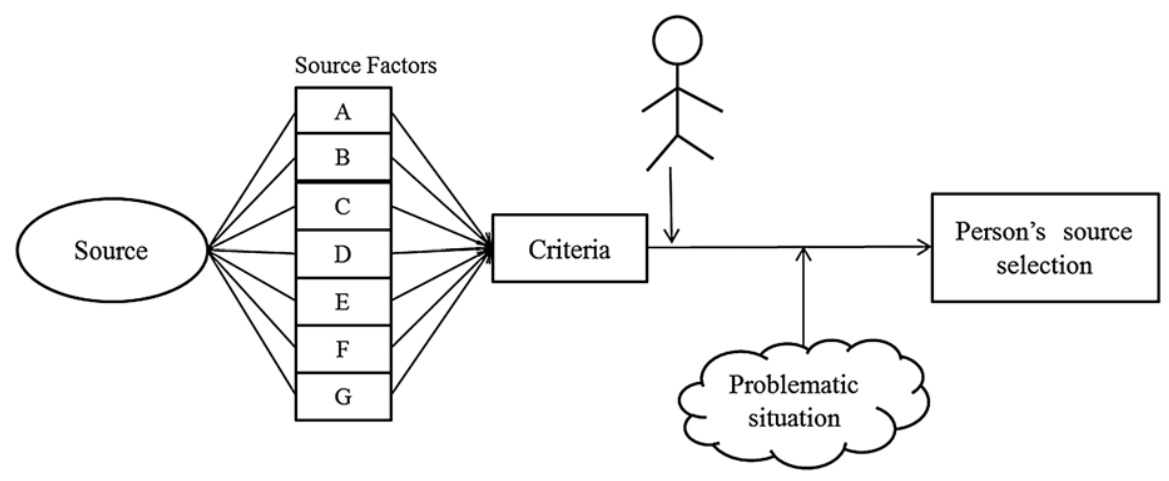

FIG. 1. Conceptual framework for examining source selection.

explaining variances in health information seeking (Lenz, 1984), but more recent studies have shown that age, education level, and ethnicity influence source selection (Atkinson, Saperstein, \& Pleis, 2009; Johnson, 1997). Younger consumers were able to identify more sources (Case et al., 2004). Younger consumers, and people with a college education and with higher income, were also more likely to get health information from the newer media, such as the Internet, whereas older adults, and people with less than a high school degree and with lower income, were more likely to refer to traditional sources such as TV and health care providers (Dickerson et al., 2004; Smith, 2011; Spink \& Cole, 2001). With respect to ethnicity, Whites were more likely to obtain health information from health care providers; the Hispanic population tended to rely more on media, family, and friends; and Blacks relied more on TV and families (Geana, Kimminau, \& Greiner, 2011; Smith, 2011).

In terms of illness experience, a Pew study revealed that adults living with chronic diseases, particularly those with multiple conditions, were significantly less likely to use the Internet for health information (Fox \& Purcell, 2010). A similar finding was reported in a survey with patients from three urban primary care clinics (Dickerson et al., 2004). The analysis of the Annenberg National Health Communication Survey (ANHCS) also revealed that people with fair to poor health were more likely to obtain health information from TV and health care providers; those with good health were more likely to turn to the Internet (Smith, 2011). These results were not surprising, as chronic disease is associated with being older, African American, less educated, and living in a lower-income household (Fox \& Purcell, 2010).

In terms of psychological factors, two variablesindividuals' health beliefs and the perceived salience of the information-were identified in the CMIS model as predicators of users' use of a source (Han et al., 2010; Johnson, 1997). Two other factors, users' self-efficacy in using the technology and trust in online information, were found to affect their selection of the Internet for health information (Dickerson et al., 2004; Lemire, Paré, Sicotte, \& Harvey, 2008; Mead, Varnam, Rogers, \& Roland, 2003). In surveying users' use of sources for cancer information with respect to genetics, Case et al. (2004) identified users' domain knowledge as a factor affecting the number of sources that they could name and their preferences for sources. In the new social media environment, due to a blurring boundary between information and information contributors, the psychological factors tend to interplay with social factors. Two psychosocial factors, the similarity of individuals in the network to the user and the user's subjective norms concerning privacy and self-image, were identified as factors influencing source selection in this new environment (Newman et al., 2011; Sillence et al., 2004; Zhang, 2012a).

Based on the review, it becomes apparent that most prior studies have focused on examining users' adoption and use of one particular source, primarily the Internet. This focus inevitably prevents a comprehensive understanding of source selection as a decision-making activity that involves the evaluation of and selection from multiple options. Furthermore, most studies used the survey method, in which a list of predefined factors or criteria was provided for users to select. Thus, limited information about users' interpretations of the factors and criteria, and about the context in which the criteria were used, could be gained. In addition, most factors identified could be subsumed under source-related or user-related factors, with few going beyond the two categories. For example, few studies viewed source selection as an integral part of the information-searching process and examined it in relation to users' information needs and specific search tasks at hand. As a result, more research is needed to achieve a systematic and comprehensive understanding of consumers' source selection behavior in health information searching. This study intends to meet this need by identifying the full range of factors influencing source selection. The conceptual framework used to guide this study is presented in the next section.

\section{Conceptual Framework and Research Questions}

Figure 1 shows the conceptual framework. Because the intention of this study is to examine source selection as a decision-making behavior in the context of health 
information search, the framework draws upon theoretical perspectives and concepts from two areas: judgment and decision-making processes (Baron, 2006; Hogarth, 1987; Stanovich, 1999), and the cognitive perspective on information seeking (Belkin, Seeger, \& Wersig, 1982; Ingwersen \& Järvelin, 2005).

\section{Judgment and Decision Making}

Judgment and decision making is a cognitive process that involves information acquisition and processing. In information acquisition, individuals collect relevant information cues (also termed factors, variables, or attributes) in the environment. In information processing, they interpret, compare, contrast, and evaluate the acquired information against decision criteria (or rules) and make decisions based on the evaluation (Brunswik, 1952; Hogarth, 1987; Stanovich, 1999). In this decision-making process, factors serve as indicators of criteria and reflect the value embedded in the criteria (Brunswik, 1952). Viewing source selection as a judgment and decision-making activity, it follows that a source is selected based on users' collection of one or multiple source cues/factors (depicted as A, B, .. G in Figure 1), such as the brand of a source, and their evaluation of these cues/factors against certain criteria (depicted in the criteria rectangular), such as accessibility and quality.

\section{Cognitive Perspective to Information Searching}

The cognitive perspective on information searching views users as cognitive entities who have their own models of the world (Ingwersen \& Järvelin, 2005). They search for information to make sense of gaps, or problematic situations, in their world models to reduce uncertainty and gain a sense of coherence (Belkin, Oddy, \& Brooks, 1982; Dervin, 1983). It is the problematic situation that gives rise to users' information needs and motivates source selection and subsequent user-system interactions (Belkin, Seeger, \& Wersig, 1982; Case, 2002; Courtright, 2008; Saracevic, 1997). Thus, the selection of a source is affected not only by attributes of the source, but also by characteristics of the problematic situation (depicted by the problematic situation cloud).

Information seekers, as independent cognitive entities, also bring a slew of individual characteristics, such as demographics, personality, and knowledge status, when interacting with an information source. Thus, user-source interaction is situated in a layered context, which consists of cognitive and emotional factors (Saracevic, 1997). As a result, source selection is also likely to be affected by the characteristics of the information seeker (depicted by the stick figure).

Based on the framework, the following research questions are proposed:

1. What source factors/cues affect users' selection of sources for health information?

2. What criteria do users employ in selecting sources for health information?
3. What characteristics of information seekers affect their selection of sources?

4. What characteristics of problematic situations affect users' selection of sources?

5. Are there any other factors that affect users' selection of sources for health information? If so, what are they?

\section{Research Methods}

The interview method was adopted in this study. It is a commonly used method to tap into users' cognitive activities with respect to the information-seeking process, including the selection of sources (Wildemuth, 2009).

\section{Participants}

Thirty participants who had searched for health information were recruited to participate in the interviews. Recruitment messages were posted to a university-wide listserv that reaches students, faculty, staff, and alumni. Fliers were posted on several public bulletin boards in libraries, music stores, coffee shops, local restaurants, grocery stores, and churches. At the same time, the snowballing technique was used to ask participants to recommend others to participate.

To ensure that participants had actually searched for health information about a particular meaningful incident, for themselves or for someone they cared for, a screening survey was put in place. The survey consisted of five questions asking for, respectively, age, gender, ethnicity, experience with health information search, and a brief description of a health-related incident for which they had searched for information. Forty-six potential participants, in total, completed the survey questionnaire. Based on the survey responses, those who did not report a rich incident of searching for health information were filtered out. As a result, 30 were selected and contacted individually for further interviews. The interviews were scheduled at the participants' convenience and at a place where they felt comfortable. Consequently, about one half of the interviews were conducted at a private laboratory on campus and the other onehalf at places designated by the interviewees.

\section{Data Collection Procedure}

The interviews consisted of two sections. In the first section, participants were presented with a list of 15 sources and asked to indicate which they had used for health information. These sources were identified from the literature (e.g., Fox \& Jones, 2009; Pennbridge et al., 1999; Rutten, Arora, Bakos, Aziz, \& Rowland, 2005; Warner \& Procaccino, 2004) and were roughly grouped into six major categories:

1. Interpersonal sources, including (a) doctors or other health care providers, (b) family members, friends, and (c) someone with similar conditions; 
2. Traditional mass media, including (a) print media (newspapers, magazines, pamphlets, or other printed materials) and (b) TV;

3. Traditional Internet sources, including (a) web search engines and (b) health websites (i.e., hyperlink-based websites. If participants mentioned using the social networking component of a health website, such as online communities on WebMD, they were considered as using Web 2.0 sources);

4. Web 2.0 sources, including (a) Wikipedia, (b) blogs, (c) support groups, online communities, or listservs, (d) generic social networking sites, (e) Really Simple Syndication (RSS) feeds/e-mail newsletters, and (f) YouTube;

5. Libraries; and

6. Government agencies/social services.

Participants were also encouraged to add sources that they had used but were not on the list. Then, for sources identified as being used, they were asked to describe their motivations or reasons for using these sources. In the process, we encouraged the participants to situate their use/ non-use of a source in particular situations whenever possible and to briefly describe the instance in which the source was used. This source-oriented approach falls short in eliciting detailed contexts for source selection instances, but allows us to understand users' criteria for selecting and using a wide range of sources, which is necessary for achieving a comprehensive understanding of source selection behaviors. In addition, due to the time-consuming and laborintensive nature of interviews, studies using the interview method often have a limited number of participants (Sonnenwald \& Wildemuth, 2001). Focusing on sources allows us to collect as many different perspectives on source selection as possible from a comparatively small sample size.

Nevertheless, we recognized that rich context is necessary for illuminating relationships between source selection decisions and users' problematic situations and cognitive activities (Charmaz, 2006). Thus, in the second section of the interview, the critical incident interview technique was adopted (Flanagan, 1954). The participants were asked to recall their most recent or most memorable incident of looking for health-related information, beginning by describing the situation that motivated the search. Then they were asked to describe the informationsearching process in terms of the sources that they had used. For each source, they were asked to describe why they chose the source and how they used the source. Each interview lasted from 1 to 2 hours.

\section{Data Analysis}

Participants' demographics, experience with health information search, and use of information sources were analyzed using descriptive statistics. The interview transcripts were imported into Nvivo 9.0 software (QSR
International Inc., Burlington, MA) and analyzed using the qualitative content analysis method (Zhang \& Wildemuth, 2009). Before the analysis, the transcripts were read a few times to become familiar with the content. At the same time, an initial coding schema was developed based on the conceptual framework. The schema consisted of two major categories of codes: one subsumed attributes or characteristics of the source, the user, and the problematic situation; and the other subsumed users' criteria for selecting sources. Criteria are rules by which users select a source. A list of criteria identified from the existing literature, such as authority, trustworthiness, accessibility, usability, and readability, constituted the preliminary codes (e.g., Cline \& Haynes, 2001; Eysenbach et al., 2002; Eysenbach \& Kohler, 2002).

The coding unit is a theme, specifically a factor associated with sources, users, or problematic situations, or a criterion that guides users for a source selection decision. As the factors are attributes of a source (e.g., author), the user (e.g., learning style), or a problematic situation (e.g., emergency), they could be easily identified by reading the transcripts. Criteria were mostly inferred from the factors or the latent meaning of a coding unit. For example, the comment, "Google is the place I go to because it is right there on my computer and it is also on my phone. It is the first thing I can go to," was coded as accessibility of a source (Google). The factor that indicates accessibility is Google's ease of access attribute. For this comment concerning Wikipedia, "I have used it because it comes up in the searches that I do online but, I am really sketchy about it because I know that people can just change things. So, it's not like it is my main 'go-to' source," two factors were identified, ease of access and editorial process, which point to two criteria, respectively: accessibility and quality of Wikipedia as a source. As the latter coding example shows, when a coding unit contained multiple factors or criteria, it was coded multiple times. To improve the validity of the coding, the author and a trained graduate student coded a subset of the transcripts independently using the initial coding schema. At the same time, an open coding process was followed to allow new categories to emerge from the data (Glaser \& Strauss, 1967). The results of the two coders were compared and several discussion sessions were held to solve discrepancies. As a result, a refined coding schema with more detailed codes was generated.

Next, the refined coding schema was applied to code all the transcripts. In the coding process, the constant comparison method was used; that is, when coding a new text into a category, the text was compared with those already assigned to the category (Glaser \& Strauss, 1967). Whenever necessary, memos were created to document the attributes of the categories as well as relationships between categories (Charmaz, 2006). To examine the coding reliability, the same graduate student coded $50 \%$ of all the transcripts and the percentage agreement between the two coders reached $87.6 \%$. The discrepancies were solved by discussion. 


\section{Results}

Participants' Demographics and Use of Health Information Sources

Of the 30 participants, $19(63.3 \%)$ were females and 11 (36.7\%) were males. The breakdown of their ethnicity was as follows: 20 were White or Caucasian; four were Asian; three were African American; and three were Hispanic. Their ages ranged from 18 to 69 years old (mean $=40.2$; standard deviation $[\mathrm{SD}]=16.3$ ). Two (ages 58 and 61, respectively) had a high school degree; five (age range, 18-20 years) were in the process of getting a college degree; 16 (age range, 22-69 years, with eight below 40 years old and eight above 40 years old) had a college degree; and the remaining seven (age range, 38-67 years, with one below 40 years old and six above 40 years old) had some postgraduate degrees. Their occupations also varied, and included student, software engineer, laboratory technician, hairstylist, product designer, product manager, theater technical director, florist, and administrative assistant. Their self-reported experience with health information search ranged from 1 to 40 years $($ mean $=14.3 ; \mathrm{SD}=10.8$ ).

Of the 15 listed sources, all participants reported using multiple ones, ranging from six to 15 . Several participants also mentioned using additional sources, including the University Health Services (UHS), Blue Cross Blue Shield's nurse line, pharmacists, and National Public Radio (NPR) programs. As a result, each participant, on average, used 11 sources for health information $(\mathrm{SD}=1.98)$.

\section{Factors Affecting Source Selection}

In this study, participants reported seeking information on a wide variety of health topics, ranging from healthy lifestyles (exercise and diet), causes of symptoms (e.g., seizures), and the severity of a condition, to treatment options and prognoses. Their selection of sources to fulfill these information needs was affected by many different factors. Based on the conceptual framework and the research questions, the factors were organized into three main categories: factors related to sources, factors related to users, and factors related to the problematic situation giving rise to the information needs. Two additional categories of factors emerged from the data, including user-source relationships and social influences.

Source-Related Factors and Corresponding Criteria. A source is a repository that carries and provides content. Thus, an information source consists of two components, a container and the content in the container. Both have an impact on source selection.

Source as a Container of Content. Table 1 shows attributes associated with source as a container that were mentioned by the participants as influencing source selection. These attributes served as indicators for four criteria: accessibility, quality, usability, and interactivity.

Ease of access refers to whether a source is readily accessible. Sources were more accessible when they were always available (e.g., search engines and online communities), showing up on the first page of Google search results (e.g., Wikipedia), within a reasonable physical distance (e.g., libraries and parents), and could be reached within an acceptable time frame (e.g., "You have to make an appointment to see a doctor."; "Friends were with me at the moment."). Ease of access points to a rule for source selection decision making: sources should be accessible (accessibility).

A number of factors (or source attributes) were mentioned by the participants as indicators of source quality, including:

- Brand: When a source, be it a website or a health professional, had a recognizable brand, such as WebMD or Dr. Oz, or was associated with an accredited or a familiar institute, such as Mayo Clinic, Blue Cross Blue Shield, Women's Health magazine, or the National Library of Medicine, it was more likely to be selected.

- Education, occupation, and experiences: In the case of interpersonal sources (family, friends, and doctors), if a person was a health care professional or was knowledgeable about a particular condition (because they had firsthand experience or read a lot), they were more likely to be chosen.

TABLE 1. Source-related factors that affected source selection and the corresponding criteria

\begin{tabular}{|c|c|c|c|}
\hline Criteria & Source factors & Description & Participants, $n(\%)$ \\
\hline Accessibility & Ease of access & Whether a source is easily available and accessible & $30(100)$ \\
\hline \multirow{7}{*}{$\begin{array}{l}\text { Quality: trustworthiness } \\
\text { and authoritativeness }\end{array}$} & Brand & Whether the brand of a source is well-known & $12(40)$ \\
\hline & $\begin{array}{l}\text { Education, occupation, } \\
\text { and experiences }\end{array}$ & $\begin{array}{l}\text { Whether an interpersonal source is a health professional or whether } \\
\text { he/she has expertise on a subject }\end{array}$ & $26(86.7)$ \\
\hline & Scope & The range of topics that a source covers & $19(63.3)$ \\
\hline & Look and feel & Whether a source, particularly a website, is professionally designed & $5(16.7)$ \\
\hline & Editorial process & How the content in a source was edited & $13(43.3)$ \\
\hline & Popularity & Whether a source is a popular source & $4(13.3)$ \\
\hline & Platform & Whether a source is delivered through a particular platform & $6(20.0)$ \\
\hline Usability & Ease of use & Whether a source is easy to use & $25(83.3)$ \\
\hline Interactivity & Interactions supported & Whether a source allows preferred ways of interaction & $18(60.0)$ \\
\hline
\end{tabular}


- Scope: Scope refers to the range of information covered by a particular source. Participants looked at scope from different perspectives, including whether a source was comprehensive, covering a wide range of topics (e.g., Google and WebMD); whether it was medical-specific (e.g., Mayo Clinic); or whether it specialized in a particular condition (e.g., the Amyotrophic Lateral Sclerosis [ALS] national organization and specialists).

- Look and feel: Look and feel refers to the visual aspect of a source, particularly whether a website is professionally designed in terms of color and layout.

- Editorial process: The editorial process mainly refers to how a source handles its content, specifically how the content is edited. For example, blogs were considered unreliable because anyone can contribute content. Conflicting views were expressed toward Wikipedia, with 10 participants pointing out that Wikipedia was not credible because anyone can edit it, but one arguing that it is because of this editing process that inaccurate information would not stay long.

- Popularity: Popularity refers to whether a source is popular. For example, one participant commented on his/her use of Google: "It is so popular and so many people search different things on it."

- Platforms: A platform refers to the infrastructure through which a source is delivered. Different platforms tended to render different levels of trust. It was typical for participants to trust and select books and certain health websites (e.g., "They were my son's drug books so I knew that they were accurate."), but not SNSs ("It always fascinates me how this information appears and I didn't take anything to heart.”)

These factors point to two dimensions of quality: trustworthiness and authoritativeness. The former refers to the incentive for a source to be truthful or biased, and the latter refers to whether the content is truthful or correct. These two dimensions tended to co-mingle (O'Keefe, 2002).

Ease of use refers to whether a source offers sufficient functionality (e.g., search by condition, symptom checker, and functions supporting cognitive activities, such as comparison) and whether the functions are effective and easy to use. It also refers to whether a source has a well-organized information architecture to support easy navigation. This factor served as an indicator of the usability rule for source selection: sources should have sufficient usability.

Interactions supported refers to the ways in which users can interact with sources. Participants talked about interactions from several aspects:

- The initiation of the interaction. For example, one participant reported using his/her insurance company as a source because the company would send him/her mail, reminding him/her to visit the site and pushing related health information to him/ her;

- The form of interaction. For example, several participants expressed a preference for doctors because they could "have a face-to-face with the doctor";

- Actions that can be afforded by a source. As an example, one participant commented on the reason to use books: "I like to have something tangible in my hand so I can highlight notes and refer back to it";

- Interaction experience. For example, one participant commented that he used search engines because they "can be tailored to our immediate needs in a really quick way."

Interactions supported apparently indicates the decision rule that sources should allow users to interact with them in preferred and personalized ways (interactivity).

Content in the Source. Content attributes that affected source selection are listed in Table 2. These attributes indicated four criteria: relevance, usefulness, usability, and quality of the content.

Topicality refers to whether the content of a source is related to the topic of interest. In most cases, being topically relevant was necessary for the selection of a source. A typical example is that participants generally reported reviewing keywords in search results before investigating the result. Topicality is an indicator of the relevance of the content to the user.

Three content attributes, presentation format, specificity, and readability, indicated the usefulness (or utility) of the content. The presentation format refers to whether the content is presented in formats deemed helpful for fulfilling

TABLE 2. Content attributes that affected source selection and the corresponding criteria

\begin{tabular}{|c|c|c|c|}
\hline Criteria & Content attributes & Description & Participants, $n(\%)$ \\
\hline Relevance & Topicality & Whether the content is about the topic of concern & $14(46.7)$ \\
\hline \multirow[t]{3}{*}{ Usefulness } & Presentation format & Whether the content is presented in a preferred format & $13(43.3)$ \\
\hline & Specificity & Whether the content is specific or general & $8(26.7)$ \\
\hline & Readability & Whether the content is easy to understand & $8(26.7)$ \\
\hline Usability & Ease of navigation & Whether the content is presented in a way that is easy to follow & $4(13.3)$ \\
\hline \multirow{6}{*}{$\begin{array}{c}\text { Quality: trustworthiness } \\
\text { and authoritativeness }\end{array}$} & Author & Who contributes the content & $17(56.7)$ \\
\hline & Advertisement & Whether the information seems like ads & $6(20.0)$ \\
\hline & Publication date & Whether the content is up-to-date & $2(6.7)$ \\
\hline & Misspellings & Whether there are misspellings & $4(13.3)$ \\
\hline & Accuracy & Whether the content is accurate & $2(6.7)$ \\
\hline & Completeness & Whether the content is complete & $2(6.7 \%)$ \\
\hline
\end{tabular}


particular needs. In numerous cases, participants preferred information in visual formats. For example, they chose YouTube and blogs that provided videos for information about exercises and physical therapies, and chose the Google Image search when trying to figure out whether their symptoms were caused by certain conditions. Specificity refers to whether the content provides a sufficient level of detail concerning a particular topic. At the beginning of a search, participants tended to favor general information. As the search went on, their needs became more specific. This cognitive development would affect source selection, as one participant commented:

[I began with Google because] I wanted to just get some general information and what to do. I kind of started out general and then I got specific as I learn[ed] more. Then I went to the surgeon, I had all these questions and he talked about his plan for me and his diagnosis. Then I went out and did more research, which was more refined and more specific, because I had more information and knew more about what we were going to do.

Readability refers to whether the content is easy to understand. This attribute was mainly related to medical terminologies. For example, one participant commented on TV programs: "they are usually pretty good about breaking things down into layman's terms." Another commented on the non-use of government sources:

A lot of [the government online sources] are for the practitioners in that field so they have a lot of jargons and lengthy journal articles when a one-sentence explanation would do. They don't quite break it down into layman's terms.

The usability of a source was indicated not only by the ease of use of the technological platform that bears the content (source as a container), but also by the ease of navigation of the content, specifically whether the content was presented in a way that is easy to follow. For example, one participant explained the reason for using Wikipedia:
I just like the way they present information. They give you an introduction to the topic and then there is this table of contents and you can click on the chapter that you might be particularly interested in.

Similarly, quality of a source was indicated not only by the attributes of sources as a container, but also by a number of content attributes, among which four were superficial, including author/provider, publication date, advertisements, and misspellings. When the content was contributed by doctors or subject experts (e.g., "The content in WebMD was contributed by doctors.") and published recently, with no advertisements and misspellings, a source was more likely to be considered of high quality and was more likely to be used. The remaining two attributes, accuracy and completeness, concerned the substance of the content. The accuracy was often judged by comparing the content from one source to one's own knowledge base or to information from other sources. The completeness was judged based on whether necessary information concerning a subject was provided. For example, one participant considered a site about a medical condition incomplete when no information about treatments and potential side effects was provided.

Information-Seeker Factors. Four categories of userrelated factors were identified as influential to sourceselection behaviors: knowledge status, personal preferences, socioeconomic status (SES), and the intention of an information search attempt, as shown in Table 3.

Participants' knowledge status included their mental models of a source, and their knowledge about the topic of interest. Participants' mental models of sources were often manifested as heuristics. For example, one participant believed that: "[Government sources] just got data, [for example], what are the survival rates for lung cancer. They are not going to have, like, treatment options."

Another commented that "MedlinePlus does not work well for [finding information concerning] alternative medicines." Several other participants also commented that they do not use Facebook, YouTube, and blogs because these

TABLE 3. User-related factors that affected source selection

\begin{tabular}{|c|c|c|c|}
\hline Categories & User factors & Description & Participants, $n(\%)$ \\
\hline \multirow[t]{2}{*}{ Knowledge status } & Mental models of a source & Users' perceptions of a source & $9(30.0)$ \\
\hline & Domain knowledge & Users' domain knowledge about the topic of interest & $3(10.0)$ \\
\hline \multirow[t]{5}{*}{ Personal preferences } & Habit & Whether the use of a source becomes a habit & $23(76.7)$ \\
\hline & Learning style & $\begin{array}{l}\text { An individual's natural patterns of acquiring and processing } \\
\text { information }\end{array}$ & $4(13.3)$ \\
\hline & Attitude or affection toward a source & Whether an individual likes a source or not & $9(30.0)$ \\
\hline & Personal interest & Whether the subjects covered by a source is of interest to the user & $21(70.0)$ \\
\hline & Privacy concern & To what degree an individual is concerned with privacy & $14(46.7)$ \\
\hline SES & Health insurance & Whether an individual has health insurance & $4(13.3)$ \\
\hline Intention & Intention of information searching & Problem solving vs. monitoring & $20(66.7)$ \\
\hline
\end{tabular}

Note. SES = socioeconomic status. 
TABLE 4. Situation-related factors that affected source selection

\begin{tabular}{|c|c|c|c|}
\hline Categories & Situation factors & Description & Participants, $n(\%)$ \\
\hline \multirow[t]{5}{*}{$\begin{array}{l}\text { Characteristics of } \\
\text { the health problem }\end{array}$} & Acute versus chronic & $\begin{array}{l}\text { Whether the health problem of concern is of an emergent nature } \\
\text { or is chronic }\end{array}$ & $7(23.3)$ \\
\hline & Time when it occurs & Time when the health problem occurs & $1(3.3)$ \\
\hline & Severity & Whether the health problem is serious & $7(23.3)$ \\
\hline & Rarity & Whether the health problem of concern is common or rare & $4(13.3)$ \\
\hline & Stigma & Whether the health problem is stigmatized & $8(26.7)$ \\
\hline \multirow{3}{*}{$\begin{array}{l}\text { Characteristics of } \\
\text { the need }\end{array}$} & Search for self or for others & Whom the search is conducted for, self or others & $2(6.7)$ \\
\hline & Specificity of the needs & Whether the information needed is specific or general & $10(33.3)$ \\
\hline & Types of information needed & Types of information that an individual intends to look for & $15(50.0)$ \\
\hline
\end{tabular}

sources "do not have health information." In terms of users' knowledge about the topic of interest, some participants pointed out that when the domain knowledge was lacking, they turned to search engines, partially due to a lack of knowledge about appropriate sources to which to refer. On the other hand, when a topic was familiar, it was likely that they had developed a list of sources for it. For example, one participant acknowledged that when he/she tries to find information about exercise, he/she goes to livestrong.com.

Five aspects of personal preferences were identified. First is habit. When participants were familiar with a source, they were more likely to use it repeatedly, which some participants termed "habits." For example, one participant commented on his/her use of doctors as a source for health information: "I would say from growing up, before the Internet arrived, my parents [would say]: 'If you are ill, go see a doctor or go to a clinic.' So, it's just, kind of, old-school, how I've been programmed."

The use of several others sources, including libraries, Google, WebMD, and Blue Cross Blue Shield's website, were also attributed by the participants to habit.

The second personal preference is learning style, which refers to individuals' natural patterns of acquiring and processing information. A few participants explicitly acknowledged that they preferred sources providing visual information, such as WebMD, YouTube, Google Image search, and Wikipedia, because they were a "visual person."

Third is an individual's attitude or affection toward a source. For example, one participant cited, "I am not a big government person," as a reason for not using government sources; another commented on the non-use of Wikipedia: "I think it might just be a personal preference. It is just not a favored source of mine."

The fourth aspect has to do with an individual's personal interests on health-related subjects. For example, a couple of participants attributed their viewing of the Dr. $O z$ TV show and visits to its website to their personal interest in healthy lifestyles; another mentioned that he/she used Yahoo!'s homepage for health information because of an interest in basic health topics and how to stay in shape.

The fifth aspect of personal preferences is related to an individual's concern about privacy. When an individual is conscious about privacy, he/she is less likely to use interpersonal sources and SNSs, but more likely to use sources that allow anonymity. For example, one participant commented: "I'm not the kind of person that likes to disclose my health information to people. And, even though they're friends, and pretty close, I still don't want to be that open, I guess."

One SES-related factor, whether participants had health insurance, was explicitly mentioned by several participants as influencing source selections, as one of them commented: "Aren't social services more for people who don't have insurance? [. . .] I have always had private insurance so I've always gone to my doctor."

Participants' intention while performing an information search was also found to affect source-selection decisions. When the intention was to retrieve information to solve a particular problem, they were more likely to actively search for information, asking questions of family, friends, and health professionals, searching on the web for both websites and user-generated content, or visiting libraries. But when the intention was to monitor information on topics of general interest, they tended to refer to mass media sources, such as TV, newspapers, magazines, and radios, or portal sites, such as Yahoo!

Characteristics of the Problematic Situation. Two categories of factors related to the problematic situation that motivates information searches were identified: characteristics of the health problem of concern and characteristics of the need that users intended to address, as shown in Table 4.

Characteristics of the health problem that affected source selection included whether it is acute or chronic, the time when the problem occurs, the severity and rarity of the problem, and whether it is stigmatized. When a problem was acute, participants were more likely to visit doctors. For example, one participant commented: 
TABLE 5. User-source relationship factors that affected source selection

\begin{tabular}{lllll}
\hline Criteria & \multicolumn{1}{c}{ Factors } & Description & Participants, $n(\%)$ \\
\hline Familiarity & $\begin{array}{l}\text { Previous experience } \\
\text { Relevance }\end{array}$ & $\begin{array}{l}\text { Whether a source has served an individual well in the past } \\
\text { Similarity/shared experience }\end{array}$ & $\begin{array}{c}\text { Whether a source (mostly interpersonal) is similar to the user or whether } \\
\text { the source has a shared experience with the user }\end{array}$ & 22 (73.3) \\
Trustworthiness & Strength of social ties & Whether an interpersonal source has a close social tie to the user & $8(26.7)$ \\
\hline
\end{tabular}

If something changes drastically, suddenly, I'll go ask a health professional first. I don't spend a lot of time trying to see what other people think about it. I just go to the doctor and say, "this is what's happening."

In contrast, participants with chronic conditions were more likely to use online communities as a source of information. One reason was that these users may have learned sufficient objective or factual information about the condition over time, and would benefit more from subjective experiential information from people with similar conditions.

The time when a health problem occurs influenced the source selection by constraining users' access to certain sources. For example, one participant reported that, at one time, her husband had an emergency (severe back pain) at night. Because they did not want to wake up the children, she looked for information in a medical reference book and on the web, called a nurse line, and waited until morning to send him to the emergency room.

For severity, when a health issue was not considered serious, such as rashes and headaches, participants were more likely to turn to web search engines or friends for information; in situations considered life-threatening, they would immediately turn to emergency rooms or health professionals.

In terms of rarity, when the condition was rare, participants were more likely to use online forums and communities, identifying people with similar conditions and communicating with them. This was partially because health websites often provide limited information on rare diseases.

For stigmatization, when a condition was stigmatized, such as herpes, participants were more likely to use the web for information, whereas for less stigmatized subjects, such as the use of creatine and the treatment of ALS, participants would turn to family and friends for information before scheduling an appointment with a doctor.

Characteristics of the need that affected source selection included search for self or for others, the specificity of the health concern, and the type of information wanted. One participant acknowledged that when he/she searches information for others, he/she would prefer sources with visual information, such as images, but when he/she searches for self, he/she would avoid using sources like search engines to avoid visually disturbing information. In information searches, users are not always certain about what information they need for their concerns. When the needs were specific, such as information about Medicare, or about whether a drug was covered by insurance, participants tended to go to specific sites, such as the U.S. Food and Drug Administration (FDA) or the Blue Cross Blue Shield site. When the needs were more general and less certain, for example, how to live a healthy life, how to diagnose and treat autism, and what certain symptoms signify, the search became more exploratory and participants often turned to search engines or portal sites, such as Yahoo!, to expose themselves to a wide range of sources. Some also turned directly to health professionals to seek help. In many cases, participants also associated certain types of information with certain sources. It was typical that they turned to search engines and health websites for "objective" or "factual" information, and to friends with similar experiences or online communities for what they termed "human aspects" information, including personal opinions, experiences, advice, and how others feel about their disorders.

Other Categories of Factors. Two additional categories of factors were identified from the data as affecting participants' source-selection decisions: user-source relationships and social influences.

User-Source Relationships. User-source relationships were built upon user-source interactions over time or established by the similarity between the user and the source. Factors in this category, shown in Table 5, indicated three criteria for source selections: familiarity, relevance, and trustworthiness.

Previous experience refers to whether an individual has used a source in the past and whether the source has served him/her well. This experience rendered users' familiarity with a source. For example, one participant explained his/ her use of MedlinePlus: "Once I was worried about my shoulder. I ended up finding very good exercises for rotator cuff [on MedlinePlus]."

Another commented on the use of WebMD: "I've gotten good information from them in the past. It tends to bear out." Yet another participant explained his/her preference for specialists: "Based on past experiences, a specialist was able to address certain symptoms that a general practitioner has overlooked."

Similarity refers to whether an interpersonal source, including family, friends, and peers in online communities, 
is similar to the user in terms of health conditions, family medical history, interests, or demographics (mainly age, gender, and geographic location). When a person was deemed similar, he/she was perceived as more relevant. Thus, similarity tends to indicate the relevance of an interpersonal source or of social media sources that mediate interpersonal communications.

The strength of social ties refers to the closeness of the relationship between an interpersonal source and the user. This relationship rendered the trustworthiness of the source. In this study, participants expressed trust in their strong ties, particularly family and close friends, believing that these close ties had their best interests in mind and feeling comfortable interacting with them. For example, one participant commented: 'I'm more comfortable speaking with family members, especially if it is something more personal." In other cases, strong ties were appreciated because of their shared life experiences with the information seeker and their knowledge about the individual's health history, as one participant explained why his wife was a source for him: "She might remember something I forgot." Another commented on family members: "They know me, know my history."

Social Influences. Social influences are associated with the social environment in which an individual is situated. Two major factors were identified: whether a source is recommended by trusted others, and social norms, as shown in Table 6.

When a source was recommended by someone, particularly someone trusted by the user, it was more likely to be trusted and used. Thus this factor tended to serve as an indicator of the quality of a source (trustworthiness and authoritativeness). A typical situation where recommendation matters a great deal was the selection of doctors. One participant's comment illustrates this: "What I try to do is go to a primary care physician [whom I knew] long enough and we've discussed enough overall health, that, when he recommends a specialist I have faith in the person that he is recommending."

This factor also applied to other sources. For example, a couple of participants reported relying on reference librarians to point them to relevant sources in libraries; one

TABLE 6. Social influence factors that affected source selection

\begin{tabular}{lccc}
\hline Criteria & Factors & Description & $\begin{array}{c}\text { Participants, } \\
n(\%)\end{array}$ \\
\hline Quality & $\begin{array}{c}\text { Recommended } \\
\text { by trusted } \\
\text { others }\end{array}$ & $\begin{array}{c}\text { Whether a source is } \\
\text { recommended by } \\
\text { other people } \\
\text { Appropriateness }\end{array}$ & $6(20.0)$ \\
Social norms & $\begin{array}{c}\text { Whether use of a source } \\
\text { complies with } \\
\text { generally accepted } \\
\text { social norms }\end{array}$ & $10(33.3)$ \\
\hline
\end{tabular}

reported using blogs recommended by more experienced friends for vegetarian recipes; one read journal articles recommended by her dermatologist; and another watched the $D r . O z$ TV show because it was recommended by her parents.

Social norms influence source selection by affecting an individual's perception of whether using a source is appropriate and acceptable behavior. Consulting doctors on health issues was a generally accepted norm, as one participant commented: "[Doctors] have the knowledge and I feel more comfortable.... I don't feel as uncomfortable, as opposed to friends. I don't mind talking about it to doctors. They should be the one to [talk to]."

Another widely accepted norm was discussing health concerns only with familiar others; as one participant put it: "I might talk to somebody, but they are never strangers." However, this norm did not apply to a few participants, who commented that seeking health information from friends, particularly for serious conditions, was an inappropriate behavior as it would affect privacy and self-image. In addition, several participants considered discussing health concerns in the social media environment as inappropriate, as these platforms were made for connecting with friends and seeking entertainment. Thus this factor tended to indicate the appropriateness of using a source.

\section{Discussion}

By framing source selection as a decision-making activity in the information-searching process and drawing upon decision-making theories and the cognitive perspective on information searching, this study contributes to a more comprehensive and systematic understanding of consumers' selection of sources for health information from several aspects. First, by examining users' selection of a wide range of sources, we expanded the current view of factors that affect source selection in health information searching instances. Table 7 provides an overview of the factors identified. The discussion will focus on those less studied in prior research, shown in italics.

Most factors associated with source as a container have been examined extensively in prior studies on health information search, as outlined in the literature review. There were two exceptions: platform and interactions supported. The platform emerged as a distinct influencing factor with the emergence of social media (e.g., blogs, Wikis, and SNSs). Unlike other platforms that preceded them, social media allow anyone to contribute content, and as a result, information was perceived as less credible. Moreover, due to the platform's social nature, many users were concerned about privacy and self-image, which prevents them from associating the platform with health information seeking. Interactions supported by a source (interactivity) have been mentioned in a few articles, and they referred mainly to whether a site provides multimedia content (Escoffery et al., 
TABLE 7. Categories of factors that influenced source selection

\begin{tabular}{|c|c|c|c|}
\hline \multirow{2}{*}{$\begin{array}{l}\text { Categories } \\
\text { Source: source as a } \\
\text { container }\end{array}$} & \multicolumn{3}{|c|}{ Factors $^{\mathrm{a}}$} \\
\hline & $\begin{array}{l}\text { Ease of access } \\
\text { Brand } \\
\text { Profession or expertise } \\
\text { Scope }\end{array}$ & $\begin{array}{l}\text { Look and feel } \\
\text { Editorial process } \\
\text { Popularity }\end{array}$ & $\begin{array}{l}\text { Platform } \\
\text { Usability } \\
\text { Interactions supported }\end{array}$ \\
\hline $\begin{array}{l}\text { Source: content of the } \\
\text { source }\end{array}$ & $\begin{array}{l}\text { Presentation format } \\
\text { Specificity } \\
\text { Easy to understand } \\
\text { Topicality }\end{array}$ & $\begin{array}{l}\text { Ease of use } \\
\text { Author } \\
\text { Advertisement } \\
\text { Publication date }\end{array}$ & $\begin{array}{l}\text { Misspellings } \\
\text { Accuracy } \\
\text { Completeness }\end{array}$ \\
\hline User-related factors & $\begin{array}{l}\text { Knowledge status: } \\
\text { Mental models of a source } \\
\text { Domain knowledge }\end{array}$ & $\begin{array}{l}\text { Personal preferences: } \\
\text { Habits } \\
\text { Learning styles } \\
\text { Affection toward a source } \\
\text { Personal interests } \\
\text { Privacy concerns }\end{array}$ & $\begin{array}{l}\text { SES: } \\
\text { Health insurance } \\
\text { Information search intentions }\end{array}$ \\
\hline Situation-related factors & $\begin{array}{l}\text { Characteristics of the health problem: } \\
\text { Acute versus chronic } \\
\text { Time when it occur }\end{array}$ & $\begin{array}{l}\text { Severity } \\
\text { Rarity } \\
\text { Stigmatized }\end{array}$ & $\begin{array}{l}\text { Characteristics of the need: } \\
\text { Search for self or for others } \\
\text { Specificity of the needs } \\
\text { Types of information needed }\end{array}$ \\
\hline User-source relationships & $\begin{array}{l}\text { Previous experience } \\
\text { Similarity/Shared experience }\end{array}$ & Strength of social ties & \\
\hline Social influences & Recommended by trusted others & Social norms & \\
\hline
\end{tabular}

Note. ${ }^{\text {at }}$ talics indicates that the factor was less studied in the health information searching literature.

2005; Kim, Eng, Deering, \& Maxfield, 1999). In this study, by examining interactivity from the user's perspective, we expanded understanding of the meaning of this concept. Users perceived source interactivity from multiple aspects, including how the content was delivered (users expressed preferences to have the content push to them), what actions they could perform (users wanted to be able to highlight and annotate, as well as to track data over time), forms of interaction (face-to-face was preferred), as well as whether the interaction was tailored for them (whether the interaction with a source was personalized).

Among content-related factors, topicality, a basic level of relevance identified in information retrieval (IR) research concerning document selections (Borlund, 2003), ironically received little attention in the prior literature on health information source selection. The lack of attention to this factor may be because most studies examine health information searches as an active behavior, and being topically relevant is a necessary condition for a source to be selected. However, a significant part of health information searches consists of passive monitoring behaviors, such as casually browsing news websites or Facebook during lunch break, or browsing a wall of pamphlets or watching TV when sitting in the waiting room in a clinic. In these cases, topically relevant information is more likely to attract users' attention and influence them, which is consistent with findings from prior studies that users are more likely to attend closely to details of a message and to invest the effort to think closely about the content of the message if it is of personal relevance (O'Keefe, 2002).

As has been discussed in the literature review, prior studies have identified a slew of user-related factors, mostly demographic and psychosocial factors, such as age, education, income, health conditions, domain knowledge, selfefficacy, health beliefs, concern for one's own health, and health insurance, as affecting source selection (Dickerson et al., 2004; Case et al., 2004). This study augmented this list with additional cognitive and affective factors, including users' mental models of a source, personal preferences (learning styles, affection toward a source, personal interests, and privacy concerns), and information search intentions (problem solving vs. monitoring information on topics of general interest). Although these factors were rarely mentioned in the literature in the health domain (Case, Andrews, Johnson, \& Allard, 2005), studies in information science (IS) have long pointed out that they affect users' interactions with IR systems (Belkin, Oddy, \& Brooks, 1982; Ingwersen \& Järvelin, 2005; McKenzie, 2003; Wildemuth, 2004), and their judgment of document relevance, which Saracevic (2007) termed cognitive and affective relevance. This study indicated that these factors also influence source selection in health information searching.

Studies in IS also revealed that characteristics of a problematic situation (manifested as search tasks), such as task complexity, importance, and routineness, have an impact on source selection in work-related tasks (Agarwal, Xu, \& Poo, 2011; Ashford, 1986; Byström \& Järvelin, 1995; Courtright, 2008; Kuhlthau, 1999; Xu, Tan, \& Yang, 2006). In studying document relevance, Saracevic (2007) termed relevance in relation to the problematic situation as situational relevance. Several studies in the health domain have discussed the impact of users' general health status, particularly whether an individual has multiple chronic conditions, on source 
selection (Dickerson et al., 2004; Smith, 2011), but few examined the impact of the specific situation that motivates the information search. Our results suggest that more attention needs to be paid to how features of a particular health problem (e.g., acute vs. chronic, and severity) and features of users' needs in the situation (e.g., types of information needed: personal experiences or practical advice) affect source selection.

The other infrequently discussed factor in prior health information search studies was whether source selection is affected by recommendations from trusted others. Studies on source selection in academic settings suggested that if a source was recommended by trusted others, it was more likely to be trusted and used (Rieh, 2002; Rieh \& Hilligoss, 2008). This phenomenon is a reflection of the cognitive authority theory that accounts for influences of entities deemed proper by individuals (Wilson, 1983). Our results suggest that cognitive authorities also have an impact on the selection of health information sources.

Our second contribution is that we made distinct the differences between two concepts: source attributes and criteria. Criteria are decision rules followed by users; and attributes are indicators of the criteria (Wang \& Soergel, 1998). In other words, criteria mediate the influence of source factors on source selection. Moreover, we identified not only criteria indicated by source-related factors, but also criteria indicated by other categories of factors. Figure 2 shows a schematic model of relationships between categories of factors, criteria, and source selection decisions.

As shown in Figure 2, users evaluate sources mainly based on source attributes and user-source relationships. These attributes and relationships are associated with the following criteria: accessibility, quality, usability, interactivity, relevance, and usefulness. For example, doctors are a preferred source for the quality of the information they can provide, and Wikipedia is preferred for its readability (usefulness).

Nevertheless, source selection was not exclusively determined by these factors. It was also influenced by factors related to the user, to the problematic situation, and to social influences. For example, a user who is a visual learner (learning style) may find sources providing images and videos (content presentation) more useful; a user who is conscious about privacy may prefer a source that maintains anonymity (anonymity); and when a health problem occurs at night (problematic situation), an individual could forgo preferred sources such as the emergency room (quality) and refer to more accessible source like the web (accessibility). Thus, additional criteria, such as familiarity, affection, anonymity, and appropriateness emerged from the influence of these factors. It is worth noting that the criteria list is not intended to be exhaustive or complete.

The third contribution of this study is that it expanded the current view of two major concepts, cost and benefit, involved in source selection. Source selection is a result of cost-benefit analyses from a decision-making perspective. In prior studies, cost was often associated with the accessibility of a source, and benefit with quality. Such associations are manifested in two dominant views of source selection. One is the least effort principle, suggesting that accessibility dominates source selection and quality plays a minor role; the other view argues that source quality is a more important factor (Xu et al., 2006). The criteria identified in the study suggest that cost not only refers to efforts needed to access a source (e.g., accessibility, usability, and interactivity), but could also refer to cognitive effort needed to understand the content (usefulness and familiarity) and social risks associated with using the source (appropriateness and anonymity). Similarly, benefit not only refers to source quality, but can also refer to the usefulness and relevance of the source.

Moreover, the criteria identified, particularly affection and anonymity, suggest that source selection is not all based on rationale calculations of costs and benefits; sometimes, emotions determine the selections. This is particularly true in the health domain. For example, users may not use close family members as a source because they do not want them to be worried; and they could choose a doctor because

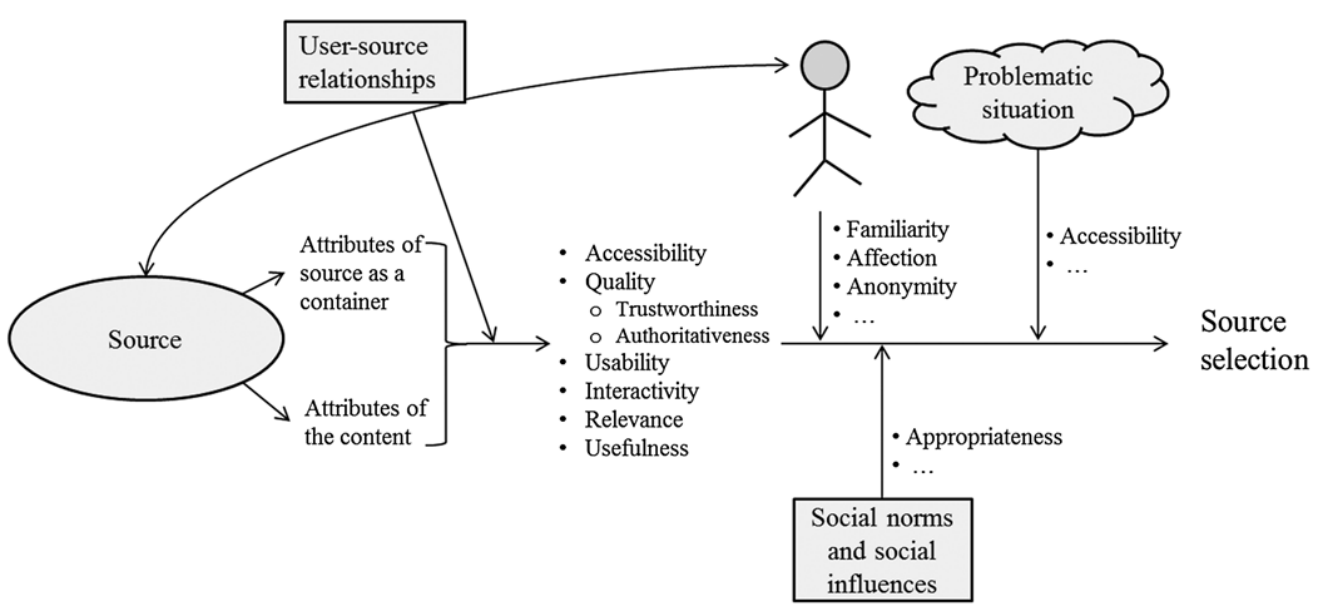

FIG. 2. A schematic model of health information source selection. 
he/she has been really nice. This corroborated findings from previous studies that patients might bypass more knowledgeable sources, such as physicians, to ask questions of someone they know for the comfortableness (Dervin, Nilan, \& Jacobson, 1982; Johnson, 1997).

Accessing proper sources for information is an important component of health literacy and is critical for empowering consumers to participate in health care decision making (NNLM, 2012). Thus, identifying factors and criteria that influence source selection has important implications for the design of health information services and information systems. The overarching implication that emerged from the results is that one-size-fits-all services or system interfaces would not serve health consumers well. In providing access to health information sources, health information services or systems should not only make sources more accessible and teach users skills in evaluating information quality, but also personalize access by taking into consideration various contextual factors, including users' learning styles, knowledge statuses, concerns about privacy, characteristics of their problematic situations (e.g., rarity of the condition and types of information needed), as well as social norms of a particular user population.

Several more specific design implications can be derived from the findings. First, the findings concerning users' perceptions of source interactivity (source as a container) suggest that health information systems and services should give users options for how to interact with them at different user-system interaction points (e.g., receiving content, reading content, and sharing content), so as to allow them to set up a personalized mode of interaction. For example, participants in this study pointed out that they would like to have the content being pushed to their e-mail accounts, to highlight and annotate content, and to track data over time. Participants also expressed preferences for face-to-face communication, which suggests that systems can provide video content to render more communication cues to those who find it helpful. Second, the influence of two user-related factors, personal interests and information search intentions (problem solving vs. monitoring), suggests the importance of providing information on subjects of personal interest to users in information environments where browsing tends to take place, such as portal sites, Facebook, news websites, or hospital waiting rooms. Personalizing these information environments will be likely to offer more "teachable moments," and effectively improve users' knowledge on a particular subject.

Third, the influence of the situational factor-types of information needed-suggests that users tend to resort to social media for information concerning personal experiences, opinions, and advice. To help users easily identify such sources, search engines can categorize search results into different content blocks based on types of information, such as results from health websites and results from online communities. It also implies that health information services or systems may want to consider collecting and preserving patients' personal experiences posted on social media platforms for users to access.
Fourth, the social influence factor-recommendations by trusted others-suggests that sources are more likely to be trusted if recommended by trusted others. To promote consumers' use of quality information, health information services may consider utilizing SNSs and online communities as a medium for recommending quality health information sources.

\section{Conclusion}

Most studies on source selection in health information search have focused on users' selection of one source or on their evaluation of source quality, which prevents researchers from gaining a systematic understanding of factors influencing source selection decisions. Addressing this limitation directly, we explored consumers' selection of a wide range of sources for health information and found that source selection decisions were not only affected by source-related factors, but also by user-related factors, user-source relationships, characteristics of the problematic situation, and social norms. Some of the factors, such as information platforms and types of information needed, became distinct due to an increased use of social media to share personal experiences among consumers. In addition, many factors, particularly those related to users' cognitive and emotional states and to the problematic situation, while being recognized as important factors affecting general information search behaviors, have rarely been studied in health information source selection. Future studies should attend to the influence of these factors. Moreover, we identified about a dozen criteria that mediate the influence of the five categories of factors on source selection, suggesting that source selection is not solely dependent on source accessibility and quality, but also on other decision rules. The identification of the factors and criteria significantly expanded our current understanding of the nature of cost-benefit analyses involved in users' selection of sources for health information.

It should be noted that this study has limitations. First, it examined source selection based on participants' selfreported data, which rely heavily on recall. It is possible that participants, sometimes, might unconsciously rationalize former irrational decisions. In future studies, multiple data collection methods, such as diaries and transaction logs, could be used in combination to partially overcome the limitations of the interview method. Second, the data collected were rich and able to suggest relationships between various factors and source selection decisions. However, as is the case in qualitative inquiries, the results are descriptive in nature and not able to provide indications of the strength of the factors or criteria in predicting source selection. Yet they can provide a stepping stone and potential directions for future studies intending to further understanding of source selection behaviors in health information searching.

\section{References}

Agarwal, N.K., Xu, Y., \& Poo, D.C.C. (2011). A context-based investigation into source use by information seekers. Journal of the American Society for Information Science and Technology, 62(6), 1087-1104. 
Ashford, S.J. (1986). Feedback-seeking in individual adaptation: A resources perspective. Academy of Management Journal, 29(3), 465-487.

Atkinson, N.L., Saperstein, S.L., \& Pleis, J. (2009). Using the internet for health-related activities: findings from a national probability sample. Journal of Medical Internet Research, 11(1), e4.

Baker, L., Wagner, T.H., Singer, S., \& Bundorf, M.K. (2003). Use of the Internet and e-mail for health care information: results from a national survey. Journal of the American Medical Association, 289(18), 24002406.

Baron, J. (2006). Thinking and deciding. Cambridge, UK: Cambridge University Press.

Belkin, N.J., Oddy, R.N., \& Brooks, H.M. (1982). ASK for information retrieval: Part I. background and theory. Journal of Documentation, 38(2), 61-71.

Belkin, N.J., Seeger, T., \& Wersig, G. (1982). Distributed expert problem treatment as a model for information system analysis and design. Journal of Information Science, 5(5), 153-167.

Borlund, P. (2003). The concept of relevance in IR. Journal of the American Society for Information Science and Technology, 54(10), 913925.

Brunswik, E. (1952). The conceptual framework of psychology. Chicago: University of Chicago Press.

Byström, K., \& Järvelin, K. (1995). Task complexity affects information seeking and use. Information Processing \& Management, 31(2), 191213.

Cangelosi, J.D., \& Markham, F.S. (1994). A descriptive study of personal, institutional, and media sources of preventive health care information. Health Marketing Quarterly, 12(1), 23-36.

Case, D.O. (2002). Looking for information: A survey of research on information seeking, needs, and behavior. Waltham, MA: Academic Press.

Case, D.O., Andrews, J.E., Johnson, J.D., \& Allard, S.L. (2005). Avoiding versus seeking: The relationship of information seeking to avoidance, blunting, coping, dissonance, and related concepts. Journal of the Medical Library Association, 93(3), 353-362.

Case, D.O., Johnson, J.D., Andrews, J.E., Allard, S.L., \& Kelly, K.M. (2004). From two-step flow to the Internet: The changing array of sources for genetics information seeking. Journal of the American Society for Information Science and Technology, 55(8), 660-669.

Charmaz, K. (2006). Constructing grounded theory: A practical guide through qualitative analysis. Thousand Oaks, CA: Sage Publications.

Cline, R.J.W., \& Haynes, K.M. (2001). Consumer health information seeking on the Internet: The state of the art. Health Education Research, 16(6), 671-692.

Courtright, C. (2008). Context in information behavior research. In B. Cronin (Ed.), Annual Review of Information Science and Technology (pp. 273-306). Hoboken, NJ: John Wiley \& Sons. doi: 10.1002/aris. 2007.1440410113

Davis, F.D. (1989). Perceived usefulness, perceived ease of use, and user acceptance of information technology. MIS Quarterly, 13(3), 319340.

Dervin, B. (1983, May). An overview of sense-making research: Concepts, methods, and results to date. Presented at the International Communication Association Annual Meeting, Dallas, TX. Retrieved from http:// faculty.washington.edu/wpratt/MEBI598/Methods/An\%20Overview \%20of\%20Sense-Making\%20Research\%201983a.htm

Dervin, B., Nilan, M., \& Jacobson, T. (1982). Improving predictions of information use: A comparison of predictor types in a health communication setting. In M. Burgoon (Ed.), Communication yearbook (vol. 5, pp. 807-830). Beverly Hills, CA: Sage Publications.

Dickerson, S., Reinhart, A.M., Feeley, T.H., Bidani, R., Rich, E., Garg, V.K., \& Hershey, C.O. (2004). Patient Internet use for health information at three urban primary care clinics. Journal of the American Medical Informatics Association, 11(6), 499-504.

Dolan, G. (2003). How do patients make use of health-related information from the Internet? Investigating the views of the public and healthcare professionals. International Journal of Consumer Studies, 27(3), 241242.
Escoffery, C., Miner, K.R., Adame, D.D., Butler, S., McCormick, L., \& Mendell, E. (2005). Internet use for health information among college students. Journal of American College Health, 53(4), 183-188.

Eysenbach, G. (2000). Recent advances: Consumer health informatics. British Medical Journal, 320(7251), 1713-1716.

Eysenbach, G., \& Kohler, C. (2002). How do consumers search for and appraise health information on the World Wide Web? Qualitative study using focus groups, usability tests, and in-depth interviews. British Medical Journal, 324(7337), 573-577.

Eysenbach, G., Powell, J., Englesakis, M., Rizo, C., \& Stern, A. (2004). Health related virtual communities and electronic support groups: Systematic review of the effects of online peer to peer interactions. British Medical Journal, 328(7449), 1166.

Eysenbach, G., Powell, J., Kuss, O., \& Sa, E.-R. (2002). Empirical studies assessing the quality of health information for consumers on the World Wide Web: A systematic review. Journal of the American Medical Association, 287(20), 2691-2700.

Fidel, R., \& Green, M. (2004). The many faces of accessibility: Engineers' perception of information sources. Information Processing \& Management, 40(3), 563-581.

Flanagan, J.C. (1954). The critical incident technique. Psychological Bulletin, 51(4), 327-358.

Fox, S., \& Jones, S. (2009). The social life of health information. Retrieved from http://www.pewinternet.org/ /media//Files/Reports/2009/PIP Health 2009.pdf

Fox, S., \& Purcell, K. (2010). Chronic disease and the Internet. Retrieved from http://pewresearch.org/pubs/1537/chronic-disease-internet-use

Geana, M.V., Kimminau, K.S., \& Greiner, K.A. (2011). Sources of health information in a multiethnic, underserved, urban community: Does ethnicity matter? Journal of Health Communication, 16(6), 583-594.

Gerstberger, P.G., \& Allen, T.J. (1968). Criteria used by research and development engineers in the selection of an information source. Journal of Applied Psychology, 52(4), 272-279.

Glaser, B., \& Strauss, A. (1967). The discovery of grounded theory: Strategies for qualitative research. New Brunswick, NJ: Aldine Transaction.

Gollop, C.J. (1997). Health information-seeking behavior and older African American women. Bulletin of the Medical Library Association, 85(2), $141-146$.

Gray, N.J., Klein, J.D., Cantrill, J.A., \& Noyce, P.R. (2002). Adolescent girls' use of the Internet for health information: Issues beyond access. Journal of Medical Systems, 26(6), 545-553.

Griffiths, K.M., \& Christensen, H. (2005). Website quality indicators for consumers. Journal of Medical Internet Research, 7(5), e55. doi: 10.2196/jmir.7.5.e55

Han, J.Y., Wise, M., Kim, E., Pingree, R., Hawkins, R.P., Pingree, S., . . . Gustafson, D.H. (2010). Factors associated with use of interactive cancer communication system: An application of the comprehensive model of information seeking. Journal of Computer-Mediated Communication, 15(3), 367-388

Hesse, B.W., Nelson, D.E., Kreps, G.L., Croyle, R.T., Arora, N.K., Rimer, B.K., \& Viswanath, K. (2005). Trust and sources of health information: The impact of the Internet and its implications for health care providers: Findings from the first Health Information National Trends Survey. Archives of Internal Medicine, 165(22), 2618-2624.

Hogarth, R.M. (1987). Judgement and choice (2nd ed.). New York: John Wiley \& Sons.

Ingwersen, P., \& Järvelin, K. (2005). The turn: Integration of information seeking and retrieval in context (The information retrieval series). Secaucus, NJ: Springer-Verlag.

Johnson, J.D. (1997). Cancer-related information seeking. Cresskill, NJ: Hampton Press.

Johnson, J.D., \& Meischke, H. (1991). Cancer information: Women's source and content preferences. Journal of Health Care Marketing, 11(1), $37-44$

Kealey, E., \& Berkman, C.S. (2010). The relationship between health information sources and mental models of cancer: Findings from the 2005 Health Information National Trends Survey. Journal of Health Communication, 15(Suppl 3), 236-251. 
Kim, P., Eng, T.R., Deering, M.J., \& Maxfield, A. (1999). Published criteria for evaluating health related web sites: Review. British Medical Journal, 318(7184), 647-649.

Kuhlthau, C.C. (1999). The role of experience in the information search process of an early career information worker: Perceptions of uncertainty, complexity, construction, and sources. Journal of the American Society for Information Science, 50(5), 399-412.

Laurent, M., \& Vickers, T.J. (2009). Seeking health information online: Does Wikipedia matter? Journal of the American Medical Informatics Association, 16(4), 471-479.

Lemire, M., Paré, G., Sicotte, C., \& Harvey, C. (2008). Determinants of Internet use as a preferred source of information on personal health. International Journal of Medical Informatics, 77(11), 723-734.

Lenz, E.R. (1984). Information seeking: A component of client decisions and health behavior. Advances in Nursing Science, 6(3), 59-72.

Manfredi, C., Czaja, R., Buis, M., \& Derk, D. (1993). Patient use of treatment-related information received from the Cancer Information Service. Cancer, 71(4), 1326-1337.

Marchionini, G. (1997). Information seeking in electronic environments. Cambridge, UK: Cambridge University Press.

McKenzie, P.J. (2003). A model of information practices in accounts of everyday-life information seeking. Journal of Documentation, 59(1), $19-40$.

Mead, N., Varnam, R., Rogers, A., \& Roland, M. (2003). What predicts patients' interest in the Internet as a health resource in primary care in England? Journal of Health Services Research and Policy, 8(1), 33-39.

Morahan-Martin, J.M. (2004). How Internet users find, evaluate, and use online health information: A cross-cultural review. CyberPsychology and Behavior, 7(5), 497-510.

Morrison, E.W., \& Vancouver, J.B. (2000). Within-person analysis of information seeking: The effects of perceived costs and benefits. Journal of Management, 26(1), 119-137.

National Network of Libraries of Medicine (NNLM). (2012). Health literacy. Retrieved from http://nnlm.gov/outreach/consumer/hlthlit .html\#A8

Newman, M.W., Lauterbach, D., Munson, S.A., Resnick, P., \& Morris, M.E. (2011). It's not that I don't have problems, I'm just not putting them on Facebook: Challenges and opportunities in using online social networks for health. Proceedings of the ACM 2011 Conference on Computer Supported Cooperative Work (CSCW '11) (pp. 341-350). New York: ACM Press. doi: 10.1145/1958824.1958876

O'Keefe, D.J. (2002). Persuasion: Theory and research (2nd ed.) Thousand Oaks, CA: Sage Publications, Inc.

O'Malley, A.S., Kerner, J.F., \& Johnson, L. (1999). Are we getting the message out to all?: Health information sources and ethnicity. American Journal of Preventive Medicine, 17(3), 198-202.

O'Reilly, C.A. (1982). Variations in decision makers' use of information sources: The impact of quality and accessibility of information. The Academy of Management Journal, 25(4), 756-771.

Oh, S., Yi, Y., \& Worrall, A. (2012, October). Quality of health answers in social Q\&A. Presented at the 74th Annual Conference of the American Society for Information Science and Technology (ASIST '12), Baltimore, MD. Retrieved from https://www.asis.org/asist2012/proceedings/ Submissions/75.pdf

Pennbridge, J., Moya, R., \& Rodrigues, L. (1999). Questionnaire survey of California consumers' use and rating of sources of health care information including the Internet. Western Journal of Medicine, 171(5-6), 302305.

Purcell, G.P., Wilson, P., \& Delamothe, T. (2002). The quality of health information on the Internet. British Medical Journal, 324(7337), 557558.

Rieh, S.Y. (2002). Judgment of information quality and cognitive authority in the Web. Journal of the American Society for Information Science and Technology, 53(2), 145-161.

Rieh, S., \& Hilligoss, B. (2008). College students' credibility judgments in the information-seeking process. In M.J. Metzger, \& A.J. Flanagin, (Eds.), Digital media, youth, and credibility (pp. 49-71). The John D. and Catherine T. MacArthur Foundation Series on Digital Media and Learn- ing. Cambridge, MA: MIT Press. Retrieved from http://mitpress.mit.edu/ books/digital-media-youth-and-credibility

Rutten, L.J.F., Arora, N.K., Bakos, A.D., Aziz, N., \& Rowland, J. (2005). Information needs and sources of information among cancer patients: A systematic review of research (1980-2003). Patient Education and Counseling, 57(3), 250-261.

Saracevic, T. (1997). The stratified model of information retrieval interaction: Extension and applications. Proceedings of the ASIS Annual Meeting, 1997, 34, 313-327. Washington, DC.

Saracevic, T. (1997). The stratified model of information retrieval interaction: Extension and applications. In C. Schwartz \& M. Rorvig (Eds.), Proceedings of the 60th ASIS Annual Meeting (vol. 34, pp. 313-327). Medford, NJ: Information Today.

Saracevic, T. (2007). Relevance: A review of the literature and a framework for thinking on the notion in information science. Part II: Nature and manifestations of relevance. Journal of the American Society for Information Science and Technology, 58(13), 1915-1933.

Savolainen, R. (2006). Time as a context of information seeking. Library and Information Science Research, 28(1), 110-127.

Silberg, W.M., Lundberg, G.D., \& Musacchio, R.A. (1997). Assessing, controlling, and assuring the quality of medical information on the Internet: Caveant lector et viewor-Let the reader and viewer beware. Journal of the American Medical Association, 277(15), 1244-1245.

Sillence, E., Briggs, P., Fishwick, L., \& Harris, P. (2004). Trust and mistrust of online health sites. Proceedings of the SIGCHI Conference on Human Factors in Computing Systems (CHI '04) (pp. 663-670). New York: ACM.

Smith, D. (2011). Health care consumer's use and trust of health information sources. Journal of Communication in Healthcare, 4(3), 200210.

Sonnenwald, D., \& Wildemuth, B. (2001, January). Investigating information seeking behavior using the concept of information horizons. Presented at the 2001 Association for Library and Information Science Education (ALISE) Conference, Washington, DC.

Spink, A., \& Cole, C. (2001). Information and poverty: Informationseeking channels used by African American low-income households. Library and Information Science Research, 23(1), 45-65.

Stanovich, K.E. (1999). Who is rational?: Studies of individual differences in reasoning. Mahwah, NJ: Lawrence Erlbaum Associates.

Toms, E.G., \& Latter, C. (2007). How consumers search for health information. Health Informatics Journal, 13(3), 223-235.

Wang, P., \& Soergel, D. (1998). A cognitive model of document use during a research project. Study I. Document selection. Journal of the American Society for Information Science, 49(2), 115-133.

Warner, D., \& Procaccino, J.D. (2004). Toward wellness: Women seeking health information. Journal of the American Society for Information Science and Technology, 55(8), 709-730.

Wildemuth, B.M. (2004). The effects of domain knowledge on search tactic formulation. Journal of the American Society for Information Science and Technology, 55, 246-258.

Wildemuth, B.M. (2009). Applications of social research methods to questions in information and library science. Englewood, CO: Libraries Unlimited.

Wilson, P. (1983). Second-hand knowledge: An inquiry into cognitive authority. Westport, CT: Greenwood Press.

Wilson, T.D. (1981). On user studies and information needs. Journal of Documentation, 37(1), 3-15.

Xu, Y., Tan, B.C.Y., \& Yang, L. (2006). Who will you ask? An empirical study of interpersonal task information seeking. Journal of the American Society for Information Science and Technology, 57(12), $1666-1677$.

Yeung, T.M., \& Mortensen, N.J. (2012). Assessment of the quality of patient-oriented Internet information on surgery for diverticular disease. Diseases of the Colon and Rectum, 55(1), 85-89.

Zhang, Y. (2012a). College students' uses and perceptions of social networking sites for health and wellness information. Information Research, 17(3), Paper 523. Retrieved from http://informationr.net/ir/17-3/ paper523.html 
Zhang, Y. (2012b, October). Consumer health information searching process in real life settings. Presented at the 74th Annual Conference of the American Society for Information Science and Technology (ASIST '12), Baltimore, MD. Retrieved from https://www.asis.org/asist2012/ proceedings/Submissions/46.pdf
Zhang, Y., \& Wildemuth, B.M. (2009). Qualitative analysis of content. In B. Wildemuth (Ed.), Applications of social research methods to questions in information and library science (pp. 308-319). Westport, CT: Libraries Unlimited. 